\title{
APLIKASI TANDA BAHAYA DI DAERAH RAWAN KEJAHATAN DENGAN ANDROID
}

\author{
Sulistiyanto \\ Fakultas Teknik Prodi Teknik Elektro Universitas Nurul Jadid \\ Email: soelis@unuja.ac.id
}

\begin{abstract}
Probolinggo Regency is a district in the province of East Java which is located between $7^{\circ} 43^{\prime} 41^{\prime \prime}-7^{\circ} 49^{\prime} 04^{\prime \prime}$ south latitude and $113^{\circ} 10^{\prime}-113^{\circ} 15^{\prime}$ East Longitude with the area of Probolinggo Regency 56,667 $\mathrm{Km}^{2}$. Probolinggo Regency has a population of 1,096,244 people with 546,492 men while 573,308 women. The development of information technology in the field of Geographic Information Systems (GIS) which can be accessed more quickly by the public with mobile phones. Criminality is a difficult problem that has a broad impact on all levels of society. Crime acts occur in many places with different incidents, which makes it difficult to determine which areas have a high level of crime. Information about crime-prone locations is needed by the community and law enforcement in this case the police. Android-based GIS is seen as an appropriate tool to be applied in this case given the advantages it has. With the application of a mapping system, places that often occur criminals will be marked, so that people who cross the area can be careful, because there have been previous messages from applications on their mobile phones. Mapping the location of crime-prone areas as a form of security enhancement that often results in crime.
\end{abstract}

Kunta Kunci : android, GIS, kawan kriminal, probolinggo,

\section{PENDAHULUAN}

Kabupaten Probolinggo adalah kabupaten di provinsi jaawa timur yang terletak antara $7^{\circ} 43^{\prime} 41^{\prime \prime}$ $7^{\circ} 49^{\prime} 04^{\prime}$ lintang selatan dan $113^{\circ} 10^{\prime}-113^{\circ} 15^{\prime}$ Bujur Timur dengan luas wilayah Kabupaten Probolinggo $56,667 \mathrm{Km}^{2}$. Kabupaten probolinggo mempunyai jumlah penduduk 1.096.244 jiwa dengan laki-laki 546,492 jiwa sedangkan perempuan 573,308 jiwa. Data dari BPS Kabupaten Probolinggo tahun 2014 (BPS, 2014).

Kriminalitas adalah permasalahan sulit yang berdampak luas kepada seluruh lapisan masyarakat. Kriminalitas memang merupakan masalah yang umum ada di manapun. Tindak kejahatan banyak terjadi di berbagai tempat dengan waktu kejadian yang berbeda, menyebabkan sulitnya menentukan daerah mana yang memiliki tingkat kerawanan tindak kejahatan. Informasi tentang banyaknya tindak kejahatan sangat dibutuhkan oleh masyarakat dan penegak hukum dalam hal ini jajaran kepolisian. Bagi semua pihak seperti masyarakat luas, informasi ini sangat berguna untuk tindakan antisipasi, khususnya bagi kepolisian membantu dalam mengambil keputusan apakah suatu daerah memerlukan pengawasan ekstra atau tidak, selain itu informasi tersebut dibutuhkan untuk mengetahui intensitas tindak kejahatan. Tingkat kriminalitas di Kabupaten Probolinggo begitu banyak, dimana Kabupaten Probolinggo mempunyai berbagai macam kasus kriminal, diantaranya : Pencurian 40 korban, pemerkosaan (cabul) 3 korban, penganiayaan 6 korban, penipuan 21 korban, pembegalan 11 korban. Berikut Tabel daerah rawan kejahatan di wilayah probolinggo. (Polres, 2018).

\begin{tabular}{|c|l|c|}
\hline No & $\begin{array}{l}\text { Nama } \\
\text { daerah } \\
\text { Rawan }\end{array}$ & $\begin{array}{c}\text { Waktu } \\
\text { kejahatan }\end{array}$ \\
\hline 1 & $\begin{array}{l}\text { Jalan } \\
\text { taman } \\
\text { maramis } \\
\text { sampai curah } \\
\text { grinting. }\end{array}$ & $17.00 \mathrm{~s} / \mathrm{d} 22.00$ \\
\hline 2 & $\begin{array}{l}\text { Jalan } \\
\text { mastrip } \\
\text { sampai arah } \\
\text { kademangan }\end{array}$ & $11.00 \mathrm{~s} / \mathrm{d} 13.00$ \\
\hline 3 & $\begin{array}{l}\text { Jalan } \\
\text { babian arah } \\
\text { timur TWSL }\end{array}$ & $10.00 \mathrm{~s} / \mathrm{d} 24.00$ \\
\hline 4 & $\begin{array}{l}\text { Jalan raya } \\
\text { wonoasih } \\
\text { sampai } \\
\text { triwung }\end{array}$ & $15.00 \mathrm{~s} / \mathrm{d} 21.00$ \\
\hline
\end{tabular}




\begin{tabular}{|c|c|c|}
\hline 5 & $\begin{array}{l}\text { Jalan raya } \\
\text { pesisir sampai } \\
\text { tongas }\end{array}$ & $17.00 \mathrm{~s} / \mathrm{d} 24.00$ \\
\hline 6 & $\begin{array}{l}\text { Jalan raya } \\
\text { clarak leces }\end{array}$ & $\begin{array}{l}04.00 \mathrm{~s} / \mathrm{d} 06.00 \\
18.00 \mathrm{~s} / \mathrm{d} 22.00\end{array}$ \\
\hline 7 & $\begin{array}{r}\text { Jalan raya } \\
\text { malasan }\end{array}$ & $\begin{array}{l}05.00 \mathrm{~s} / \mathrm{d} 07.00 \\
18.00 \mathrm{~s} / \mathrm{d} 24.00\end{array}$ \\
\hline 8 & $\begin{array}{l}\text { Jalan raya } \\
\text { tegal siwalan } \\
\text { banyu anyar }\end{array}$ & $\begin{array}{l}05.00 \mathrm{~s} / \mathrm{d} 07.00 \\
18.00 \mathrm{~s} / \mathrm{d} 24.00\end{array}$ \\
\hline 9 & $\begin{array}{l}\text { Jalan raya } \\
\text { sinto dringu } \\
\text { ke selatan }\end{array}$ & $17.00 \mathrm{~s} / \mathrm{d} 22.00$ \\
\hline 10 & $\begin{array}{l}\text { Jalan raya } \\
\text { gending }\end{array}$ & $18.0 / \mathrm{d} 24.00$ \\
\hline
\end{tabular}

\section{Dasar Teori}

\section{Sistem Informasi Geografis (SIG)}

Sistem Informasi Geografis adalah sistem informasi berbasis komputer yang digunakan untuk menyimpan dan memanipulasi informasi-informasi geografi. SIG dirancang untuk mengumpulkan,menyimpan,dan menganalisis objek dan fenomena dimana daerah geografi merupakan karakteristik yang penting atau kritis untuk dianalisis.Dengan demikian,SIG merupakan sistem komputer yang memiliki empat kemampuan dalam menangani data yang bereferensi geografi, yaitu masukan, manajemen data (penyimpanan dan pemanggilan data),analisis dan manipulasi data, dan keluaran (Sulistiyanto, 2017).

\section{Android}

Android adalah sistem operasi berbasis Linux yang dirancang untuk perangkat seluler layar sentuh seperti telepon pintar dan komputer tablet. Android awalnya dikembangkan oleh Android Inc. dengan dukungan finansial dari Google yang kemudian membelinya pada tahun 2005. Sistem operasi ini dirilis secara resmi pada tahun 2007 bersamaan dengan di dirikannya Open Handset Alliance, konsorsium dari perusahaan perusahaan perangkat keras, perangkat lunak dan telekomunikasi yang bertujuan untuk memajukan standar terbuka perangkat seluler (Suprayogi, 2015).

\section{Daerah Rawan Kriminalitas}

Daerah rawan kriminalitas adalah daerah yang memiliki angka kriminalitas/tindak kejahatan tinggi, resiko kejahatan tinggi dan potensi kejahatan tinggi pada setiap keadaan. Daerah rawan kriminalitas dapat diidentifikasi dari korban tindak kriminal, pelaku tindak kriminal, dan jumlah kejadian tindak kriminalitas (Gilang, 2014).

\section{Metode Penelitian}

Dalam penelitian ini menggunakan metode penelitian metode kuantitatif, karena kuantitatif merupakan salah satu jenis penelitian yang spesifikasinya sistemetis, terencana dan terstuktur dengan jelas. Serta untuk teknik pengembangan sistemnya menggunakan model waterfall seperti gambar 1. (Ginanjar, 2017)

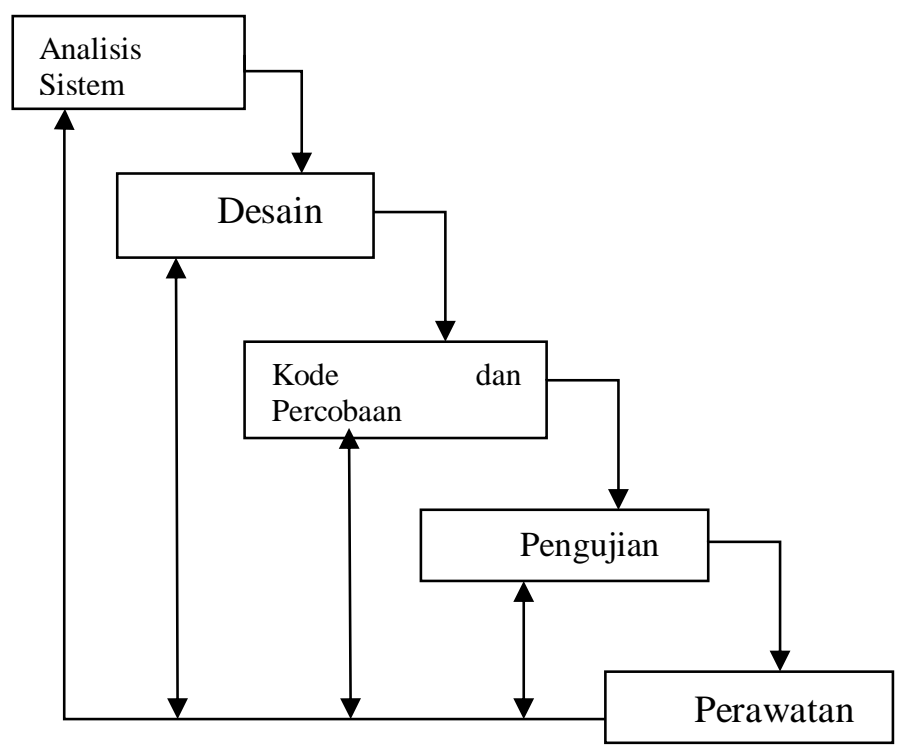

Gambar 1. Metode Waterfall

\section{Hasil dan Pembahasan}

\section{Analisis Sistem}

Penelitian dilakukan di daerah Polres Probolinggo dengan menganalisa sistem, sehingga data lokasi daerah rawan kejahatan didapatkan dari kntor polres Probolinggo.

\section{Data Flow Diagram (DFD)}

Data Flow Diagram adalah diagram atau bagan yang menggambarkan arus atau alir data dari suatu sistem yang diperinci menjadi beberapa level seperti berikut ini :

DFD Level 0 atau biasa disebut Diagram Context. 


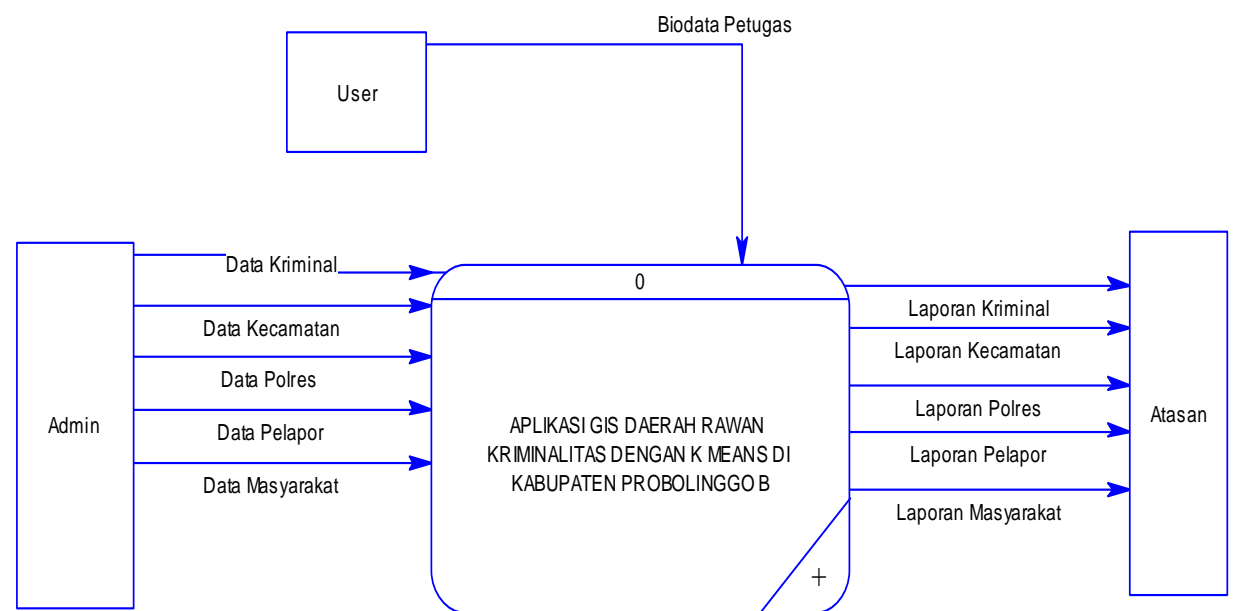

Gambar 2. Diagram Context

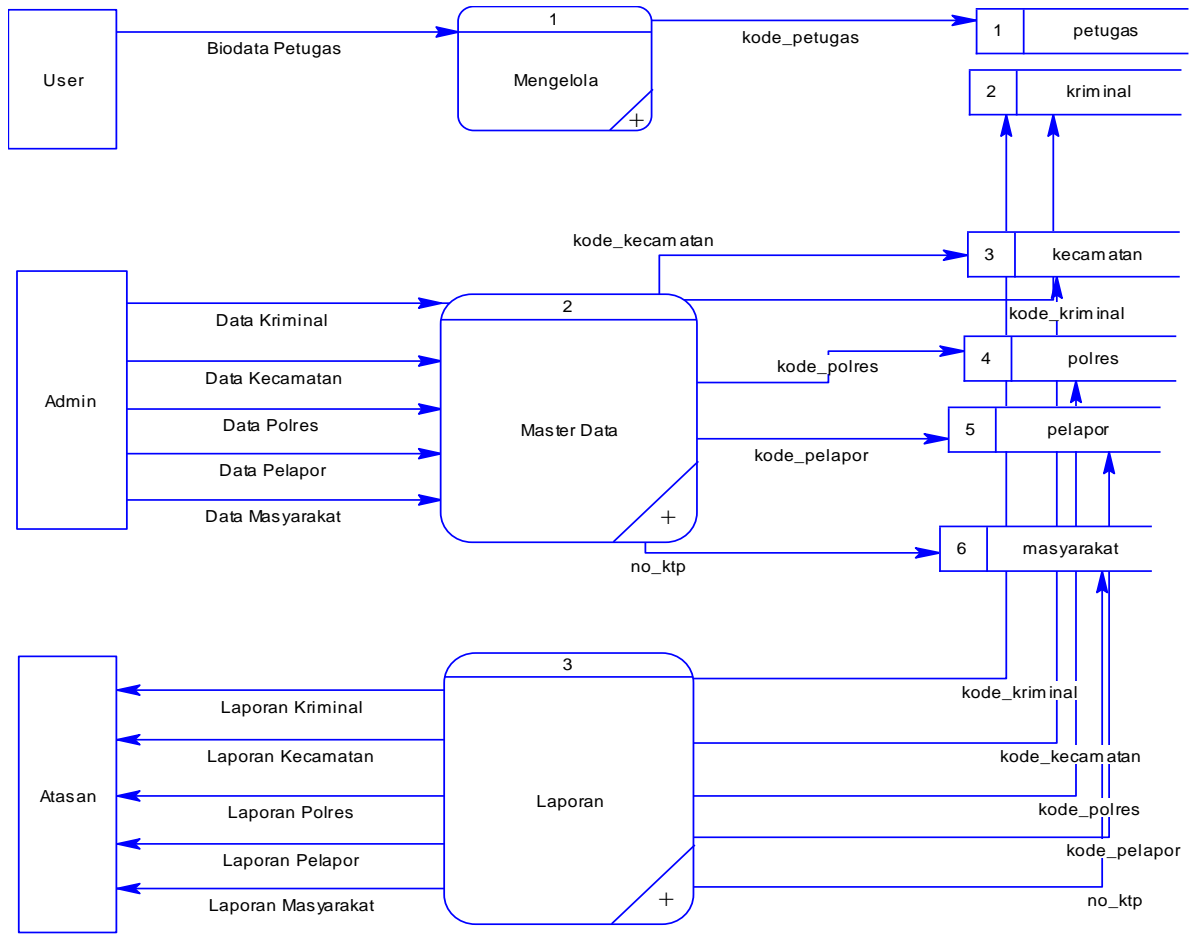

Gambar 3. DFD Level 1

\section{Entity Entity Relationship Diagram (ERD)}

Entity Relationship Diagram (ERD) adalah merupakan salah satu media analisa data yang menggambarkan pola hubungan antara entitas untuk meperoleh informasi yang membentuk kerangka sistem. Dalam rancangan ini disajikan untuk mendefinisikan isi atau struktur dari tiap-tiap file yang melalui pendekatan yaitu bentuk Context Data Model (CDM) dan Physical Data Model (PDM). 


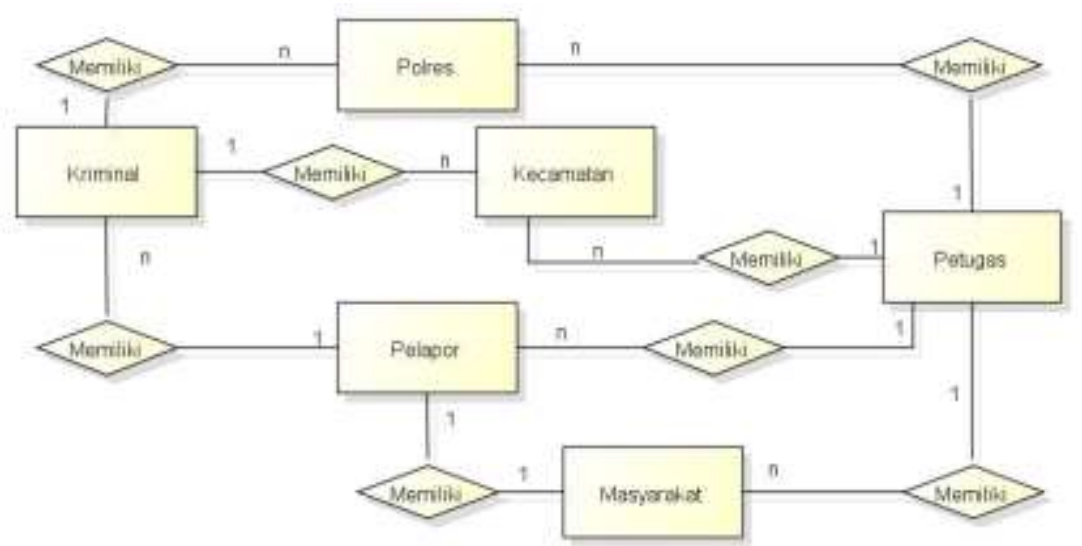

Gambar 4. Entity Relationship Diagram

Kamus Data :

Polres :id_p, nama_polres, alamat, provensi, telp. Kriminal : id, jenis_kriminal, waktu, no_telp, pelapor, tkp, id kecamatan, titik_lokasi, keterangan. Kecamatan : id_kecamatan, nama, jml_penduduk, keterangan.

Masyarakat : no_ktp, nama, alamat, jk, telp.
Pelapor keterangan, tgl.

Petugas : id_petugas, nama, username, password.

\section{Form Data Polres}

Disini data daerah rawan kejahatan yang berasal dari polres di inputkan.

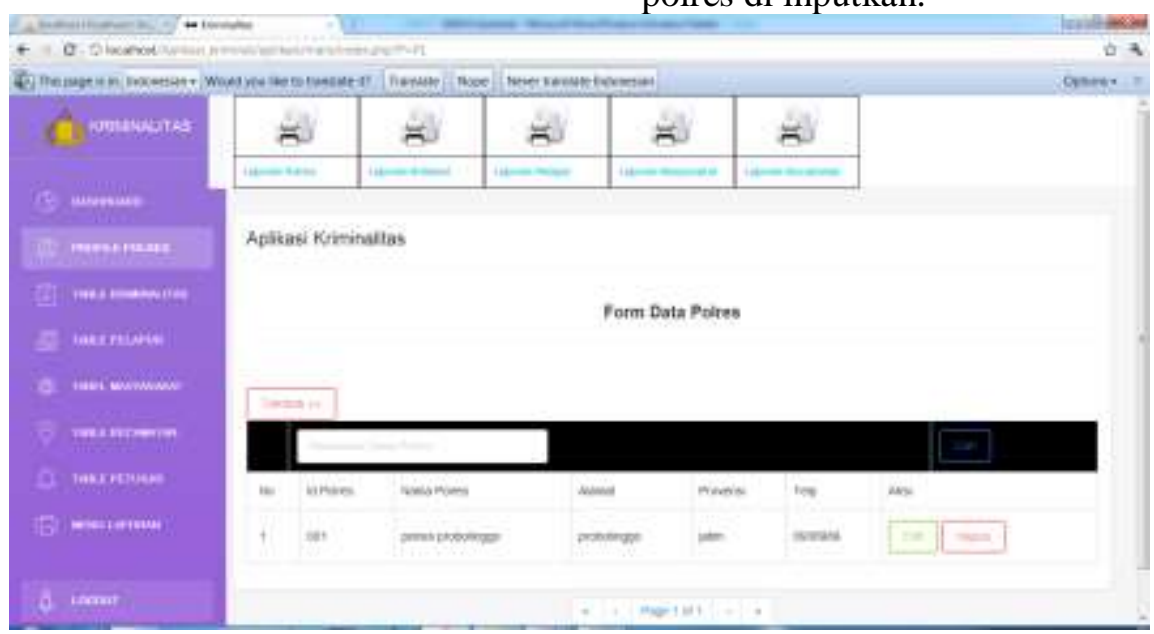

Gambar 5. Form Data Polres

Menu data pelapor untuk menginputkan data pelapor dan menampilkan data yang sudah di inputkan oleh petugas. Ketika data ada yang salah maka petugas akan mengupdate data tersebut dengan mengklik button edit begitu juga dengan button hapus. 


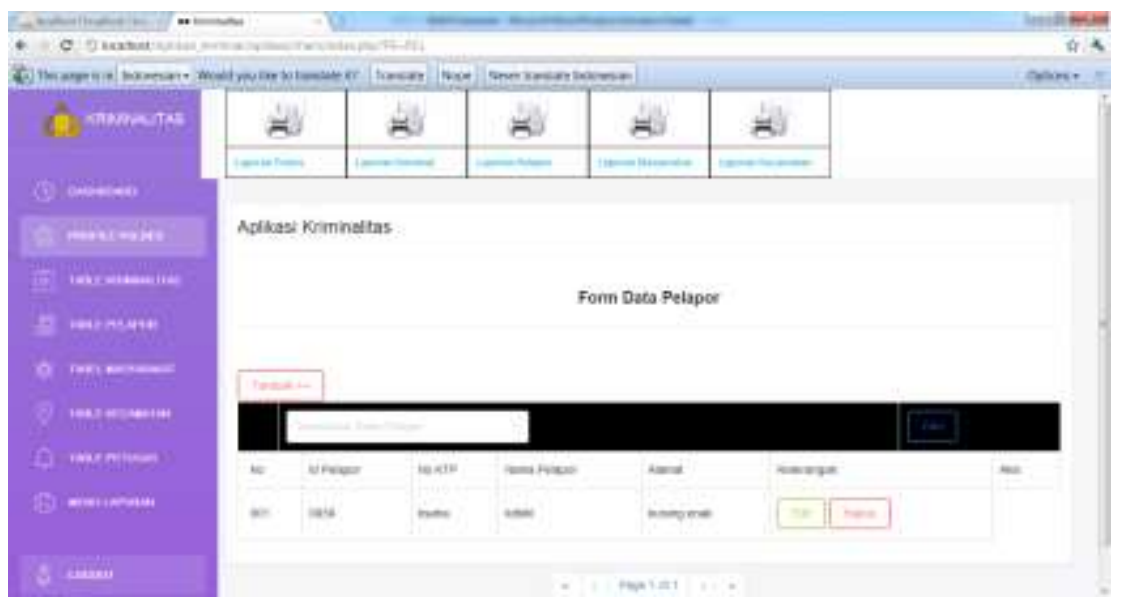

Gambar 6. Form Data Pelopor

Maps daerah Rawan Kriminal

Halaman peta tempat akan ditampilkan titik lokasi tempat rawan kriminalitas di kabupaten probolinggo.

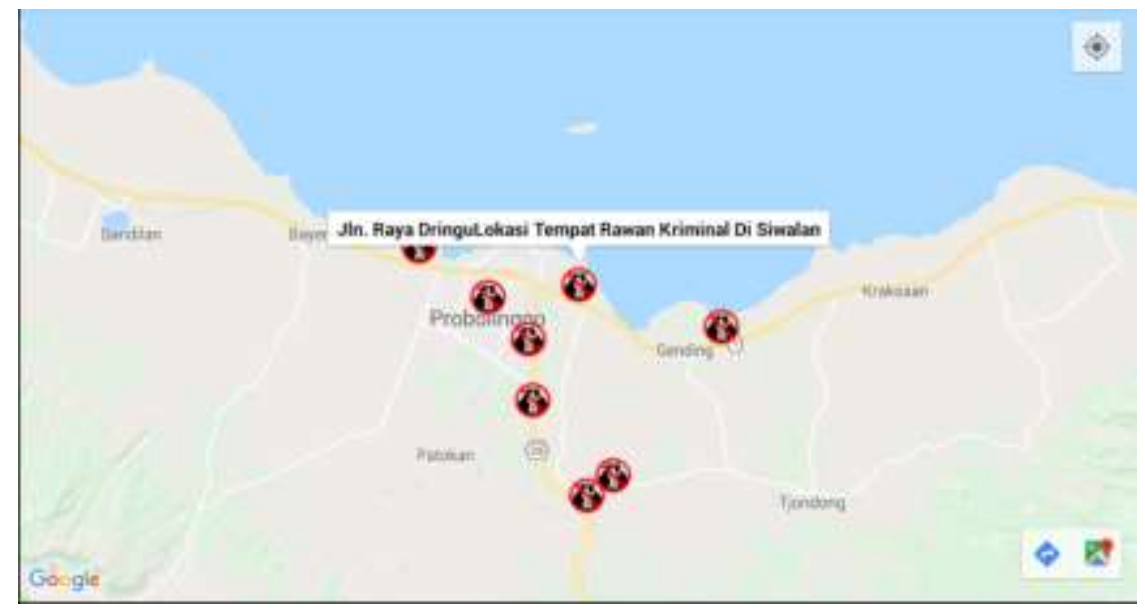

\section{Kesimpulan}

Kesimpulan berdasarkan penelitian yang telah dilakukan pada Polres Probolinggo, maka dapat diambil kesimpulan, yaitu:

- Dengan adanya sistem aplikasi pemetaan tempat yang sering terjadi kriminal akan diberi tanda, agar masyarakat yang melintasi daerah tersebut dapat berhati-hati karena sudah ada pesan sebelumnya dari aplikasi.

- Pemetaan lokasi daerah rawan kejahatan sebagai bentuk peningkatan keamanan yang sering terjadi kriminalitas.

\section{DAFTAR PUSTAKA}

BPS, P. (2014). Dalam Data warga probolinggo. Polres, P. (2018). Dalam Data Kriminal.
Arwan, P. W. (2015). PEMETAAN DAERAH RAWAN KRIMINALITAS DI WILAYAH HUKUM POLTABES SEMARANG TAHUN 2013 DENGAN MENGGUNAKAN METODE CLUSTERING. Jurnal Geodesi Undip , 04.

Gilang, Y. H. (2014). PEMETAAN DAERAH RAWAN KRIMINALITAS DI WILAYAH HUKUM POLTABES SEMARANG TAHUN 2013 DENGAN MENGGUNAKAN METODE CLUSTERING.

Nono, S. (2017). PEMETAAN DAERAH RAWAN KRIMINAL BERBASIS WEB DI WILAYAH HUKUM PENGADILAN NEGERI TASIKMALAYA. Konferensi Nasional Sistem \& Informatika .

Riza, D. O. (2015). PEMETAAN DATA KRIMINALITAS DI KOTA MALANG BERBASIS WEB GIS. Informatika Polinema, 01.

Riza, M. N. (2007). SISTEM INFORMASI PEMETAAN PROFIL KRIMINALITAS BERBASIS WEB.

Rosa, \& Salahuddin. (2013). Rekayasa Perangkat Lunak. Bandung: INFORMATIKA. 
Suarga. (2012). Algoritma Dan Pemograman. Yogyakarta: ANDI.

Sulistiyanto. (2017). PEMANFAATAN QGIS CLOUD UNTUK PEMETAAN PABRIK GULA DI JAWA TIMUR. PROSIDING SNITER , B08-1.

Suprayogi, A. (2015). PEMBUATAN APLIKASI MOBILE GIS BERBASIS ANDROID UNTUK INFORMASI
PARIWISATA DI KABUPATEN GUNUNGKIDUL. Jurnal Geodesi Undip , 241-247.

Yudi, A. (2007). K-Means - Penerapan, Permasalahan. Sistem dan Informatika , 03.

Ginanjar, W. S. (2017). PENERAPAN METODE WATERFALL PADA DESAIN SISTEM INFORMASI GEOGRAFIS INDUSTRI KABUPATEN TEGAL. Jurnal Informatika:Jurnal Pengembangan IT (JPIT) . 